\title{
Risk factors and knowledge of the elderly people about chronic kidney disease
}

\author{
Fatores de risco e conhecimento de idosos sobre doença renal crônica
}

Millena Freire Delgado ${ }^{1}$, Isabel Neves Duarte Lisboa ${ }^{1}$, Maria Isabel da Conceição Dias Fernandes ${ }^{1}$, Ana Carolina Costa Carino $^{1}$, Renata Marinho Fernandes ${ }^{1}$, Ana Luisa Brandão de Carvalho Lira ${ }^{1}$

Objective: to analyze the relationship between the risk factors and the elderly people knowledge about chronic kidney disease. Methods: this study is a cross-sectional research with 100 elderly enrolled in basic units, using a semi-structured interview. Data were analyzed using descriptive and inferential statistics. Results: most elderly people had adequate knowledge about the disease and prevention, but poor knowledge about hemodialysis. Regarding the risk factors in the elderly investigated, increased are highlighted and statistical significance of waist circumference $(p=0.049)$, smoking $(p=0.022)$ and alcohol consumption $(p=0.013)$. Conclusion: relationships between risk factors as smoking, alcoholism, increased abdominal circumference, and the knowledge of the elderly about chronic kidney disease were identified.

Descriptors: Nursing; Primary Health Care; Renal Insufficiency, Chronic; Aged.

Objetivo: analisar a relação entre os fatores de risco e o conhecimento dos idosos sobre a doença renal crônica. Métodos: estudo transversal, realizado com 100 idosos cadastrados em unidades básicas, utilizando entrevista semiestruturada. Os dados foram analisados com recurso à estatística descritiva e inferencial. Resultados: a maioria dos idosos detinha conhecimento adequado sobre a doença e a prevenção, mas conhecimento deficiente sobre a hemodiálise. Em relação aos fatores de risco presentes nos idosos destacam-se os valores aumentados e com significância estatística da circunferência abdominal $(p=0,049)$, tabagismo $(p=0,022)$ e o etilismo $(p=0,013)$. Conclusão: identificaram-se relações entre os fatores de risco tabagismo, etilismo, circunferência abdominal aumentada, e o conhecimento dos idosos sobre a doença renal crônica.

Descritores: Enfermagem; Atenção Primária à Saúde; Insuficiência Renal Crônica; Idoso.

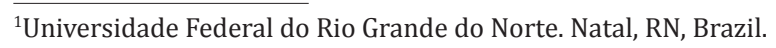




\section{Introduction}

The global scenario shows a trend towards an increase in the number of older people. The number of individuals over 60 years old between 1990 and 2013 increased from $9.2 \%$ to $11.7 \%$. By 2050 , this population will double, with an increase of over two billion. In this context, longevity is accompanied by chronic noncommunicable diseases, a public health problem due to the high prevalence, mortality, and difficulty of adherence of patients ${ }^{(1)}$.

Chronic kidney disease affects $45.0 \%$ of people over 70 years old and can double the risk of physical disability, cognitive dysfunction, and frailty ${ }^{(2)}$, among other chronic noncommunicable diseases in the elderly. The elderly are classified as a risk group for chronic kidney disease, considering the decline in glomerular filtration rate in line with the advancement of age $^{(3)}$. In this sense, the aging of the population points to a much higher proportion of patients at risk for the development of chronic kidney disease ${ }^{(4)}$.

Therefore, modifiable risk factors for chronic kidney disease such as diabetes, hypertension, dyslipidemia, obesity, cardiovascular disease, and smoking should be strictly monitored and controlled in Primary Health Care ${ }^{(5)}$. Early screening for these factors may prevent kidney disease or delay its progression among elderly patients.

Preventing chronic kidney disease is less costly to the health care system than its treatment and its repercussions. In the state of São Paulo, there was an expenditure of almost six trillion reais with hemodialysis treatment between 2008 and 2012(6). Also, the average cost of hospitalization for elderly patients with chronic kidney disease pervades approximately US $\$ 10,260^{(7)}$. Besides these expenses, individuals with this disease demonstrate a significant decrease in quality of life $\mathrm{f}^{(8)}$.

Thus, the Unified Health System reorganized its actions, focusing on the main characteristics of these diseases: the long duration and the strong interrelationship with the habits of life. Care has been given primarily to Primary Health Care, through a care mo- del focused on coordinated, continuous, organized, proactive, integrated care and with the capacity to support individuals in lifestyle changes ${ }^{(9)}$.

Also, nurses should play a relevant role in Primary Health Care, in screening for possible risk factors for the development of chronic kidney disease in the elderly, counseling on the disease and implementing intervention programs for these at-risk groups ${ }^{(10)}$. However, barriers related to patient education about chronic kidney disease were perceived at this level of care, such as the poor recognition of this disease as a problem of health professionals; lack of adequate knowledge of the primary care professionals; disability skills to educate patients about chronic kidney disease; time restriction in the patient's home visit; and lack of educational resources ${ }^{(11)}$.

This reality culminates in the lack of knowledge of patients according to research on the topic. Individuals have a serious lack of knowledge about chronic kidney disease, unaware of risk factors, forms of prevention and not sure of the available treatments ${ }^{(10)}$.

In this context, despite the poor knowledge of patients about chronic kidney disease, the influence of this deficit on the occurrence of renal disease risk factors is not clear. It is assumed that the knowledge deficit may influence the occurrence of certain renal disease risk factors. In this sense, confirming this aspect may highlight the problem, leading the scientific community and health professionals to implement interventions to facilitate the understanding of the elderly population about the prevention and early detection of chronic kidney disease risk factors to reduce the prevalence of complications and costs related to dialysis, and consequently to improve the quality of life of the elderly ${ }^{(10)}$.

From this perspective, it is questioned: does the lack of knowledge about chronic kidney disease influence the occurrence of risk factors for this disease in this patients? Therefore, this study intends to analyze the relationship between the risk factors of chronic kidney disease and the knowledge of the elderly about chronic kidney disease. 


\section{Methods}

This is a cross-sectional study, carried out from March to July 2015, in Basic Health Units located in a city in Northeast Brazil.

The study population consisted of elderly people enrolled in the selected Basic Health Units. The sample was calculated from the formula for infinite population: $n=z^{2} \alpha^{*} P^{*} Q / E^{2}$. For that, the following parameters were considered: confidence level of $95.0 \%$ $(\mathrm{Z} \alpha=1.96)$; Sampling error of $10.0 \%$; Prevalence of the event of $50.0 \%$, and a final sample of 96 elderly was calculated, being rounded up to 100 participants. The sampling process occurred for convenience and consecutively.

The inclusion criteria were: age above 60 years old, enrollment in the Family Health Strategy and participated in groups of elderly people in the selected health units. The exclusion criterion was stipulated as a cognitive deficiency.

For the selection of Basic Health Units, there was a draw considering the four zones of the city, with the purpose of better representing the population. The Northern Zone is covered by $23(43.0 \%)$ basic units; The West Zone has 12 (23.0\%) units for this service; and the South and East Zone have nine (17.0\%) health units, each. After quantitative representation, the proportion of the units with the number of participants was obtained, resulting in: Northern Zone with 43 elderly; West Zone with 23 and South and East Zone with 17 elderly, each.

The data collection was guided by a semistructured instrument, previously validated by two specialist nurses in the area of nephrology, who analyzed the appropriateness and pertinence of the content. The variables of the instrument were sociodemographic data, chronic kidney disease risk factors, and knowledge evaluation.

The variables assessed as risk factors were systemic blood pressure, body mass index, waist circumference, diabetes, physical activity, smoking and drinking habits, age, family income and gender. It should be emphasized that the data were obtained through the direct collection with the elderly. Measurement of blood pressure was performed using a palpatory and auscultatory technique, using an aneroid sphygmomanometer, duly calibrated. Therefore, it was verified that the participant was not bladder full, had not exercised before collection, ingested alcoholic beverages and/or with caffeine and had not smoked until 30 minutes before the procedure. Individuals with blood pressure $\leq 120 \times 80 \mathrm{~mm}$ of mercury ${ }^{(12)}$ were considered as normotensive.

For the measurement of the body mass index, the formula weight/height ${ }^{2}$ was used. For this, the elderly were weighed on a calibrated digital scale and the height measured using a tape measure, as well as their abdominal circumference. The body mass index was considered normal when its result was between 18.5 and 24.9 kilograms per square meter, and the circumference was considered increased when above 94 $\mathrm{cm}$ in men and over $80 \mathrm{~cm}$ in women ${ }^{(13)}$.

The variables smoking, alcoholism and diabetes were self-reported by the elderly. Physical activity was measured by the reports of the elderly, considering the frequency and duration of the activity. The elderly were considered active when they reported practicing physical activity with a frequency of three times a week and lasting at least 30 minutes $^{(14)}$.

Concerning knowledge about chronic kidney disease, the elderly were evaluated through three open questions: Do you know what chronic kidney disease is? What forms of prevention? What is hemodialysis? From the participant's response, the researchers judged the response as adequate (completely correct answer) and inadequate (completely incorrect response). It should be emphasized that the evaluation of the responses was guided by the scientific literature.

Data were collected by four researchers. Training with a two-hour workload addressed the items available in the collection instrument to minimize errors and standardize the collection. In the data collection, the elderly were invited to participate in the rese- 
arch, explaining them their purpose and technique of collection. After the acceptance, the informed consent form was read in full and signed by the participants.

The data were organized in spreadsheets in Microsoft Office Excel and processed by the Statistical Package for the Social Sciences for 19.0 for Windows, using descriptive statistics, with verification of normality of the data by the Kolmogorov-Smirnov test, considering a $\mathrm{p}<0.05$. Inferential statistics were also used by the Chi-square test, Fisher's exact test and Mann-Whitney U test, with $\mathrm{p}<0.05$.

The study complied with the formal requirements contained in the national and international regulatory standards for research involving human beings.

\section{Results}

Most participants $(80.0 \%)$ were female, had a median of 70 years old and family income of two minimum wages. Regarding the education, 47 (47.0\%) of the elderly reported incomplete elementary education, especially those with higher education (7.0\%) and illiterate (14.0\%). The level of knowledge about chronic kidney disease among the elderly interviewed is shown in Table 1.
Table 1 - Level of knowledge about chronic renal disease in the elderly attended at a Basic Health Unit $(\mathrm{n}=100)$

\begin{tabular}{lcc}
\hline \multirow{2}{*}{ Variable } & $\begin{array}{c}\text { Adequate } \\
\text { knowledge }\end{array}$ & $\begin{array}{c}\text { Inadequate } \\
\text { knowledge }\end{array}$ \\
\cline { 2 - 3 } & $\mathbf{n ~ ( \% )}$ & $\mathbf{n ~ ( \% )}$ \\
\hline What is chronic kidney disease? & $82.0(82.0)$ & $18(18.0)$ \\
What are the forms of prevention? & $58.0(58.0)$ & $42(42.0)$ \\
What is hemodialysis? & $21.0(21.0)$ & $79(79.0)$ \\
\hline
\end{tabular}

Regarding the level of knowledge, it was identified that most of the elderly had an adequate knowledge about chronic kidney disease and its forms of prevention. However, most of them presented knowledge deficits about hemodialysis.

Table 2 shows the possible risk factors present in the elderly attended at the basic health units surveyed.

Regarding the risk factors of chronic kidney disease present in the elderly investigated, systolic blood pressure above 120 millimeters of mercury, abdominal circumference above 94 centimeters, body mass index above 24.9 kilograms per meter (50.0\%), the alcoholism in 35 (35.0\%), the elderly, and the elderly are highlighted as shown in Table 2. Also, Diabetes in $25(25.0 \%)$ and sedentary lifestyle in $31(31.0 \%)$.

Table 2 - Risk factors for chronic kidney disease in the elderly enrolled in the basic health units surveyed ( $\mathrm{n}=100)$

\begin{tabular}{|c|c|c|c|c|c|c|}
\hline Variable & $\begin{array}{c}\text { Systolic Blood } \\
\text { Pressure (mmHg) }\end{array}$ & $\begin{array}{l}\text { Diastolic Blood } \\
\text { Pressure (mmHg) }\end{array}$ & $\begin{array}{l}\text { Body mass index } \\
\qquad\left(\mathrm{Kg} / \mathrm{m}^{2}\right)\end{array}$ & $\begin{array}{c}\text { Abdominal } \\
\text { circumference }(\mathrm{cm})\end{array}$ & Age & $\begin{array}{l}\text { Family } \\
\text { income }\end{array}$ \\
\hline Average & - & - & 27.8 & 97.6 & - & - \\
\hline Standard deviation & - & - & 3.8 & 10.4 & - & - \\
\hline Medium & 130.0 & 80.0 & - & - & 70.0 & 2.0 \\
\hline Minimum & 92.0 & 50.0 & 20.2 & 70.0 & 60.0 & 0.5 \\
\hline Maximum & 190.0 & 100.0 & 37.9 & 121.0 & 91.0 & 15.0 \\
\hline $\mathrm{p}^{*}$ & $<0.001$ & $<0.001$ & 0.200 & 0.200 & $<0.001$ & $<0.001$ \\
\hline
\end{tabular}


Table 3 shows the relationship between the risk factors identified in this study and the level of knowledge about the chronic renal disease in elderly patients.

Table 3 - Ratio of risk factors present in the elderly enrolled in basic health units and knowledge about the disease, forms of prevention and treatment $(n=100)$

\begin{tabular}{lccc}
\hline Variable & $\begin{array}{c}\text { Knowledge about } \\
\text { chronic kidney } \\
\text { disease }\end{array}$ & $\begin{array}{c}\text { Knowledge } \\
\text { about preven- } \\
\text { tion methods }\end{array}$ & $\begin{array}{c}\text { Knowledge } \\
\text { about } \\
\text { treatment }\end{array}$ \\
\hline Risk factors (p-value) & $0.382^{*}$ & $0.717^{*}$ & $0.579^{*}$ \\
Systolic blood pressure & $1.000^{*}$ & $0.863^{*}$ & $0.682^{*}$ \\
Diastolic Blood Pressure & $0.170^{*}$ & $0.684^{*}$ & $0.231^{*}$ \\
Body mass index & $0.782^{*}$ & $0.272^{*}$ & $0.049^{*}$ \\
Abdominal circumference & $0.546^{* *}$ & $0.294^{* * *}$ & $0.671^{* * *}$ \\
Diabetes & $0.111^{* * *}$ & $0.466^{* * *}$ & $0.183^{* * *}$ \\
Physical activity & $0.013^{* * *}$ & $0.409^{* * *}$ & $0.226^{* * *}$ \\
Drinking habit & $0.022^{* * *}$ & $0.157^{* * *}$ & $0.806^{* * *}$ \\
Smoking Habit & $0.095^{*}$ & $0.050^{*}$ & $0.206^{*}$ \\
Age & $0.667^{*}$ & $0.137^{*}$ & $0.698^{*}$ \\
Family income & $0.062^{* *}$ & $0.840^{* * *}$ & $0.346^{* *}$ \\
\hline Sex & & & \\
\hline "U deMann-Whitney Test; "Fisher's Exact Test; "**Chi-square Test & \\
& & & \\
\hline
\end{tabular}

Abdominal circumference $(\mathrm{p}=0.049)$, drinking habits $(\mathrm{p}=0.013)$ and smoking $(\mathrm{p}=0.022)$ were found to be significantly associated with the level of knowledge of the elderly investigated.

\section{Discussion}

The limits of the results of this study are related to the exclusive delimitation of the knowledge about the chronic renal disease, not extending to knowledge regarding acute renal disease and other forms of treatment, besides hemodialysis. Also, risk factors for smoking, alcoholism, and diabetes were only self-reported by the patients, and not measured by the researchers.

The results of this study contribute to nursing since they confirm the elderly as a group at risk for the development of chronic kidney disease. Although most of the risk factors identified in the elderly in the study are not directly related to the low level of knowledge about the subject. However, health promotion actions are still required for these individuals. Consequently, patients will also benefit from the results insofar as the knowledge exposed in this study will assist professionals working in primary health care to direct strategies for the empowerment of the elderly regarding the lifestyle adopted and its repercussions on health.

In the study sample, most of the elderly presented adequate knowledge about chronic kidney disease and its forms of prevention. However, a minority knew to report on hemodialysis. In this regard, the literature diverges from these findings by pointing out a serious lack of knowledge about chronic kidney disease in the individuals surveyed ${ }^{(10)}$.

Regarding the risk factors for chronic kidney disease, systemic blood pressure was elevated. Hypertension has been considered a determinant and frequent condition in chronic kidney disease ${ }^{(15)}$. Recent studies have shown a relationship between systemic arterial hypertension and chronic kidney disease. Hypertensive individuals are twice as likely to develop this disease ${ }^{(16)}$.

The body mass index and the waist circumference of the elderly investigated were above avera$\mathrm{ge}^{(13)}$. In this sense, the presence of overweight and risk of metabolic complications in these individuals is verified. Chronic kidney dysfunction is an important consequence of obesity. Obesity causes renal vasodilation and glomerular hyperfiltration, acting as compensatory mechanisms to maintain sodium balance. These offsets, along with increased blood pressure and metabolic abnormalities, can lead to glomerular lesions. Inflammation, oxidative stress and lipotoxicity, mediated by obesity, may also contribute to renal dysfunction $^{(17)}$.

The altered abdominal circumference was associated with inadequate knowledge about hemodialysis treatment in this study. Inadequate knowled- 
ge about chronic diseases and their treatments makes possible the lack of adherence to healthy living habits, such as improper diet and sedentary lifestyle, factors that culminate in obesity. Patient knowledge about the disease is a crucial factor in the process of acceptance and adherence to therapy, but in practice issues related to the treatment of chronic kidney disease are poorly explored ${ }^{(18)}$.

The habit of drinking and smoking was associated with knowledge about chronic kidney disease. In this study, although most of the elderly presented adequate knowledge about chronic kidney disease, these individuals continue to maintain unhealthy lifestyles, such as drinking and smoking, which may compromise renal function. In the elderly, the occurrence of certain risk factors related to chronic kidney diseases, such as obesity, alcoholism, and smoking may be related to lack of resources, cognitive alterations, insufficient information and lack of interest in learning ${ }^{(19)}$.

As a possible protective factor for the development of chronic kidney disease, this study pointed out the accomplishment of physical activity, mentioned by most of the elderly. To effectively manage chronic noncommunicable diseases, such as chronic kidney disease, public health systems are implementing integrated approaches that group strategies and interventions that control risk factors. Among these measures, the importance of regular physical activity that improves the quality of life and reduces the risk of these comorbidities is highlighted ${ }^{(20)}$.

\section{Conclusion}

Most elderly participants presented adequate knowledge about chronic kidney disease and the forms of prevention. However, a minority comprised the hemodialysis treatment. Overweight, hypertension and smoking were identified as the main risk factors for chronic kidney disease. Relationships between risk factors smoking, alcoholism, increased abdominal circumference, and the knowledge of the elderly about chronic kidney disease was identified.

\section{Collaborations}

Delgado MF and Fernandes MICD contributed in the project design, data collection, statistical analysis. Lisboa IND, Carino ACC and Fernandes RM contributed to the writing of the article. Lira ALBC contributed to the design, relevant critical review of content and final approval of the version to be published.

\section{References}

1. Valcarenghi RV, Lourenço LFL, Siewert JS, Alvarez AM. Nursing scientific production on health promotion, chronic condition, and aging. Rev Bras Enferm. 2015; 68(4):618-25.

2. Anand S, Johansen KL, Tamura MK. Aging and chronic kidney disease: the impact on physical function and cognition. J Gerontol A Biol Sci Med Sci. 2013; 69(3):315-22.

3. Ghaffar U, Maharjan N, Moore PC. Predictors of CKD and rate of decline in GFR in the elderly: a case-cohort study. Nephrol News Issues.2016; 30(4):38-45.

4. Tonelli M, Riella M. Chronic kidney disease and the aging population. J Bras Nefrol. 2014; 36(1):15 .

5. Ministério da Saúde (BR). Diretrizes Clínicas para o Cuidado ao paciente com Doença Renal Crônica - DRC no Sistema Único de Saúde. Brasília: Ministério da Saúde; 2014.

6. Cruz CF, Cunha GOD, Souza SRP. Cost of treatment of patients with chronic renal failure end stage in São Paulo in the period from 2008 to 2012. Sci Health. 2014; 5(1):6-11.

7. Chen B, Fan VY, Chou YJ, Kuo CC. Costs of care at the end of life among elderly patients with chronic kidney disease: patterns and predictors in a nationwide cohort study. BMC Nephrol. 2017; 18(36):1-14.

8. Santos RR, Formiga LMF, Oliveira EAR, Lima LHO, Araújo AKS, Brito BB. Qualidade de vida de pacientes com insuficiência renal crônica sob tratamento hemodialítico. R Interd. 2015; 8(3):83-92. 
9. Bruck K, Stel V, Fraser S, Goeij MCM, Caskey F, Abu-Hanna A, et al. Translational research in nephrology: chronic kidney disease prevention and public health. Clin Kidney J. 2015; 8(6):64755.

10. Khalil A, Abdalrahim M. Knowledge, attitudes, and practices towards prevention and early detection of chronic kidney disease. Int Nurs Rev. 2014; 61(2):237-45.

11. Bochud M. On the rationale of population screening for chronic kidney disease: a public health perspective. Public Health Rev. 2015; 36:111. doi: 10.1186/s40985-015-0009-9

12. Sociedade Brasileira de Cardiologia. 7a Diretriz Brasileira de Hipertensão Arterial. Arq Bras Cardiol. 2016; 107(3):1-104.

13. Associação Brasileira para o Estudo da Obesidade e da Síndrome Metabólica. Diretrizes Brasileiras de Obesidade. São Paulo: ABESCO; 2016.

14. Guedes NG, Lopes MVO, Cavalcante TF, Moreira RP, Araújo TL. Review of nursing diagnosis Sedentary Lifestyle in individuals with hypertension: conceptual analysis. Rev Esc Enferm USP. 2013; 47(3):742-9.

15. Pinho NA, Silva GV, Pierin AMG. Prevalence and factors associated with chronic kidney disease among hospitalized patients in a university hospital in the city of São Paulo, SP, Brazil. J BRAS NEFROL. 2015; 37(1):91-7.
16. Gijón-Conde T, Graciani A, Banegas JR. Resistant hypertension: demography and clinical characteristics in 6.292 patients in a primary health care setting. Rev Esp Cardiol. 2014; 67(4):270-6.

17. Hall ME, Carmo JM, Silva AA, Juncos LA, Wang Z, Hall JE. Obesity, hypertension, and chronic kidney disease. Int J Nephrol Renovasc Dis. 2014; 18(7):75-88.

18. Muniz GC, Aquino DMC, Rolim ILTP, Chaves ES, Sardinha AHL. Nursing diagnoses in patients with chronic renal failure on hemodialysis treatment. Rev Pesq Saúde. 2015; 16(1):34-40.

19. Louredo DS, Sá SPC, Camacho ACLF, Câmara VD, Louzada ABD, Rodrigues IB. The relationship between the nursing diagnosis and cognition tests performed on elderlies with Alzheimer's disease. Rev Pesqui Cuid Fundam online [Internet]. 2014 [cited 2017 Apr. 13]; 6(1):27181. Available from:http://seer.unirio.br/index. php/cuidadofundamental/article/view/2692/ pdf_1024

20. Bauer UE, Briss PA, Goodman RA, Bowman BA. Prevention of chronic disease in the 21st century: elimination of the leading preventable causes of premature death and disability in the USA. The Lancet. 2014; 384(9937):45-52. 